\title{
Soluble leucocyte adhesion molecules in diabetic retinopathy stimulate retinal capillary endothelial cell migration
}

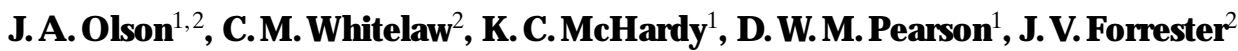 \\ ${ }^{1}$ Diabetic Clinic, Woolmanhill, Aberdeen Royal Hospitals National Health Service Trust, Aberdeen, UK \\ ${ }^{2}$ Department of Ophthalmology, University of Aberdeen, Aberdeen, UK
}

Summary Diabetic retinal neovascularisation is considered to be a consequence of retinal ischaemia caused by capillary occlusion. Capillary occlusion is the result of microvascular thrombi in which erythrocytes, platelets and leucocytes each may play a role. We investigated the role of leucocytes in this process and the subsequent angiogenic response. We studied the serum levels of the soluble leucocyte adhesion molecules soluble E-Selectin, soluble vascular cell adhesion molecule-1 (sVCAM-1) and soluble intercellular adhesion molecule-1 (sICAM-1) in the serum of 93 patients with insulin-dependent diabetes (IDDM) and varying degrees of retinopathy and 47 healthy age and sex matched control subjects. We also measured the ability of serum to stimulate retinal capillary endothelial cell migration using an assay of angiogenesis in vitro. Soluble E-Selectin and sVCAM-1 levels were raised in all patients with IDDM $(p<0.001 ; p<0.001)$ particularly those with retinopathy $(p<0.001 ; p<0.001)$. Soluble E-Selectin levels were highest in the patients with severe nonproliferative diabetic retinopathy $(p<0.001)$ and sVCAM-1 levels were highest in patients with proliferative diabetic retinopathy $(p<0.01)$. In contrast soluble ICAM-1 levels were the same in patients and control subjects $(p>0.05)$. Soluble E-Selectin levels in diabetic patients were correlated with the level of glycated haemoglobin $(p<0.05)$. Retinal endothelial cell migration-inducing (ECMI) activity was increased in patients with IDDM $(p<0.01)$ in particular in those with retinopathy $(p<0.01)$. Furthermore, in vitro ECMI activity could be blocked by antibodies to sVCAM-1 and sE-Selectin. These data point to a functional role for leucocyte adhesion in the microvasculopathy of diabetic retinopathy and may have implications for the induction of retinal angiogenesis. [Diabetologia (1997) 40: 1166-1171]

Keywords Diabetic retinopathy, leucocyte, adhesion, angiogenesis.
Diabetic retinopathy is a microvascular disease in which uncontrolled high blood glucose levels appear to play a major pathogenetic role [1]. Several theories exist regarding the pathogenesis of glucose-induced

\footnotetext{
Received: 7 January 1997 and in revised form: 19 May 1997

Corresponding author: Professor J. V. Forrester, Department of Ophthalmology, University of Aberdeen, Medical School, Foresterhill, Aberdeen AB25 2ZD, Scotland

A bbreviations: IDDM, Insulin-dependent diabetes mellitus; sE-Selectin, soluble endothelial leucocyte adhesion molecule1; sVCAM-1, soluble vascular cell adhesion molecule-1; sICAM-1, soluble intercellular adhesion molecule-1; ECMI, retinal endothelial cell migration inducing activity; NHS, normal human serum.
}

retinal microvascular damage including polyol accumulation, free radical damage and non-enzymatic glycation of essential proteins [2, 3]. In addition, high blood glucose is associated with increased blood flow in arterioles and venules which may induce some degree of shear-related endothelial damage in these vessels [4].

Neovascularisation in the retina represents an advanced stage of severe diabetic retinopathy and is considered to be a response by surviving retinal vessels to revascularise areas of ischaemic retina [5-7]. Retinal ischaemia is the direct result of increasingly widespread capillary closure caused by intravascular microthrombi, and is secondary to the glucose-induced endothelial cell damage. Ischaemic retina acts as a 
Table 1. Clinical characteristics of patients and control subjects

\begin{tabular}{|c|c|c|c|c|c|c|c|}
\hline & \multirow{2}{*}{$\begin{array}{l}\text { Control } \\
\text { subjects (47) }\end{array}$} & \multirow[t]{2}{*}{ Patients (93) } & \multicolumn{5}{|c|}{ Patient categories } \\
\hline & & & NR (18) & Mild (20) & Moderate (19) & Severe (20) & Proliferative (16) \\
\hline Age (years) & $37.1 \pm 1.5$ & $36.7 \pm 1.38$ & $29.7 \pm 1.8$ & $32.9 \pm 3.0$ & $43.0 \pm 2.9$ & $41.1 \pm 3.2$ & $38.1 \pm 3.7$ \\
\hline Duration (years) & - & - & $5.5 \pm 1.1$ & $17.7 \pm 2.8$ & $19.4 \pm 1.7$ & $18.4 \pm 1.7$ & $23.3 \pm 3.1$ \\
\hline $\mathrm{HbA}_{1 \mathrm{c}}(\%)$ & - & - & $7.9 \pm 0.7$ & $8.3 \pm 0.3$ & $9.2 \pm 0.3$ & $9.3 \pm 0.4$ & $9.7 \pm 0.5$ \\
\hline $\begin{array}{l}\text { Diastolic blood } \\
\text { pressure }(\mathrm{mm} \mathrm{Hg})\end{array}$ & - & - & $73 \pm 2$ & $75 \pm 2$ & $76 \pm 2$ & $81 \pm 2$ & $81 \pm 2$ \\
\hline Smokers (n) & & & 2 & 3 & 3 & 8 & 3 \\
\hline $\operatorname{MA}(n)$ & - & - & 0 & 1 & 5 & 4 & 2 \\
\hline
\end{tabular}

Values are means \pm SEM

NR, No retinopathy; MA, significant microalbuminuria

source of upregulated growth factor production particularly vascular endothelial cell growth factor and fibroblast growth factors [7], thereby inducing new vessel formation in the surrounding healthy vasculature.

Glucose-mediated damage to the endothelial cell results in loss of its non-thrombogenic and anticoagulant surface properties [8], thereby permitting thrombus formation. Glucose may also directly affect platelet stickiness since circulating platelets are known to be hyperaggregable in diabetic patients and this may increase the risk of intravascular coagulation and capillary closure $[9,10]$.

Recently, leukocyte activation and adhesion to the endothelium have been considered as a cause of capillary occulsion in diabetic retinopathy $[11,12]$. Leukocytes adhere to the endothelium initially via specific cell surface adhesion molecules [selectins] [13], followed by further adhesion via integrin-cell adhesion molecule interactions (ICAM-1 lymphocyte function associated antigen-1 LFA-1) and vascular cell adhesion molecule (VCAM)-1/very late activation antigen (VLA-4). After a variable period of time, the leukocyte penetrates the basement membrane and migrates into the surrounding tissue [14, 15].

Evidence for activation of leukocytes and/or the endothelium can be detected by increased levels of shed "soluble" adhesion molecules in the serum [16]. Increased levels of soluble intercellular adhesion molecule-1 (sICAM-1) in the serum of patients with severe diabetic complications has been reported previously [17], but whether this is a measure of endothelial cell activation or injury remains unclear [18]. Increased levels of soluble vascular cell adhesion molecule-1 (sVCAM-1) and/or E-Selectin in diabetic retinopathy might not only indicate endothelial cell activation but may have implications for angiogenesis since it has been shown that both of these molecules have angiogenic potency in vivo and in vitro $[19,20]$.

We have previously reported that the serum of diabetic patients contains stimulatory activity for retinal endothelial cell migration [21]. In this study we have measured the levels of sICAM-1, sVCAM and E-Selectin in 93 patients with diabetic retinopathy of increasing severity and compared the results with those from 47 age- and sex-matched control healthy individuals. We have also measured serum retinal endothelial cell migration inducing activity (ECMI) levels in a subset of 56 patients.

\section{Subjects and methods}

Clinical assessment. [a] O phthalmological evaluation: 93 patients with insulin-dependent diabetes mellitus (IDDM) were clinically assessed by direct and indirect ophthalmoscopy. Seven-field retinal photographs of each eye were taken according to the Modified Airlie House guidelines [22]. All patients also had fluorescein angiography.

[b] General medical evaluation: Supine blood pressure was measured after 5 min rest with an automated blood pressure recording device (Takeda medical digital blood pressure meter, U.A.-751, A \& D Company, Japan). The mean of three readings was recorded with hypertension being defined as a systolic blood pressure greater than $160 \mathrm{~mm} \mathrm{Hg}$ and/or a diastolic blood pressure greater than $90 \mathrm{~mm} \mathrm{Hg}$ [23]. Serum was obtained at the time of fluorescein angiography, and before any necessary laser treatment, for measurement of serum adhesion molecule levels and ECMI activity. Recent glycaemic control was assessed by measuring $\mathrm{HBA}_{1 \mathrm{c}}$ with high pressure liquid ion-exchange chromatography (Diamat: Bio-Rad Laboratories, Hemel Hemstead, UK; non-diabetic reference $<6 \%$ ) [24]. Urinary albumin/creatinine ratios were measured on three consecutive early morning midstream urine samples. Significant microalbuminuria was defined as the presence of a mean ratio of urinary albumin to creatinine greater than $2.5 \mathrm{mg} \mathrm{mol}^{-1}$ from three samples [25].

Patient characteristics. These are presented in Table 1. The control samples were obtained anonymously from blood donors attending the Aberdeen Blood Transfusion Service. The control subjects were closely matched for age and sex with the patients. Patients with retinopathy were similar for duration. $\mathrm{HbA}_{1 \mathrm{c}}$ rose with increasing severity of retinopathy. Non-smokers predominated in all patient groups. Microalbuminuria was 
found in all retinopathy groups. Patients were matched for systolic blood pressure, but diastolic blood pressure rose with worsening retinopathy. Patients without retinopathy had a shorter duration of diabetes, lower $\mathrm{HbA}_{1 \mathrm{c}}$, lower diastolic blood pressure and less microalbuminuria.

A ssessment of retinal photographs. Each field was graded individually for the presence of microaneurysms and haemorrhages, hard exudates, cotton wool spots (CWS), venous abnormalities (VB), intraretinal microvascular abnormalities (IRMA) and new vessels by using the modified Airlie House technique [22]. Fluorescein angiography was performed to confirm or refute the presence of new vessels. The overall grading was determined on the basis of all 14 fields. Retinopathy was categorised as mild (microaneurysms only), moderate (microaneurysms/haemorhages $<$ standard field $2 \mathrm{~A}$ ) or severe (microaneurysms/haemorrhages $>$ standard field $2 \mathrm{~A}$; and CWS/IRMA/VB) non-proliferative retinopathy or active proliferative (no previous laser treatment) [26].

A dhesion molecule assays. At the time of ophthalmological assessment, serum samples were obtained and stored at $-20^{\circ} \mathrm{C}$. Enzyme-linked immunoassay (ELISA) kits (Research \& Development European Products Ltd) were used to quantify levels of sICAM-1, sVCAM-1 and sE-Selectin. For sICAM-1 and sVCAM-1 this involved a double antibody ELISA using antibodies directed against different epitopes on the sVCAM-1 and sICAM-1 molecules. Internal standards of known concentration were used to construct reference curves. For sE-Selectin the second antibody was conjugated with streptavidinhorseradish peroxidase, while for sVCAM-1 and sICAM-1 horseradish peroxidase alone was used. Otherwise the methods were identical.

Retinal endothelial-cell migration inducing ( $E$ CM I) activity. The aim of this assay was to quantify an activity in serum previously shown to induce bovine retinal endothelial cells to migrate [21, 27]. In brief, bovine retinal capillary endothelial cells were selectively cultured from collagenase-digested microvessel fragments. Cells were grown in $2.5 \%$ plasma-derived serum in Glasgow's Minimum Essential Medium. Cell migration was measured by determining the ability of cells to move through polycarbonate filters in a microchemotaxis chamber (Neuroprobe, Gaithersburg, Md., USA). The filters were coated with $10 \mathrm{mg}$ $1^{-1}$ fibronectin for $60 \mathrm{~min}$ at $37^{\circ} \mathrm{C}$. Serum samples were diluted to obtain a protein concentration of $10 \mathrm{~g} \mathrm{l}^{-1}$. The serum samples were added to the lower wells of the chamber $(28 \mathrm{ml})$ and $43 \mathrm{ml}$ of cells at a concentration of $0.4 \times 10^{6} \mathrm{ml}^{-1}$ endothelial cells was added to the upper chamber. Following $4 \mathrm{~h}$ incubation at $37^{\circ} \mathrm{C}$ the filters were fixed in $37 \%$ alcohol for $7 \mathrm{~min}$. They were then rehydrated in distilled water for $3 \mathrm{~min}$. The non-migrated cells were then wiped off the upper surface of the filter and the remaining migrated cells on the lower surface of the filter were stained with Coomassie Blue. The filter was then mounted on a glass slide and the migrated cells counted with $\mathrm{a} \times 25$ objective and $\times 10$ eyepiece. Ten fields of vision were counted per well and the mean (1 SD) of six wells was determined.

In order to account for day-to-day retinal endothelial cell migration variation in the test samples, test sera were run against a known standard of pooled normal human serum (NHS). The pooled NHS was obtained from 20 normal healthy volunteers and was aliquoted and stored at $-20^{\circ} \mathrm{C}$. The results of ECMI activity were expressed as follows:

No. of cells migrating in 10 high powered fields in response to test sera
No. of cells migrating in 10 high powered fields in response to pooled NHS

Values of $1.0=$ no activity greater than pooled NHS

$$
>1.0=\text { increased ECMI activity }
$$$$
<1.0=\text { decreased ECMI activity }
$$

Significant results were obtained at $p<0.05$ (1 SD).

In selected serum samples, in which the test sera had shown positive ECMI activity, specific antibodies to VCAM or E-Selectin (Research \& Development European Products Ltd, Abingdon, UK) were incorporated with the serum samples to determine any blocking effect on ECMI activity (see Results).

E thical approval was obtained from the Joint Ethical Committee of Grampian Health Board and Aberdeen University. Patients gave informed signed consent.

Statistical analyses were performed on an Apple Macintosh PC using Instat 2.01 (Graph Pad Software, San Diego, CA, USA) and Statworks 1.3 (Cricket Software Inc., Philadelphia, Pa., USA) statistical analysis packages. Results are expressed as mean \pm SEM, except where indicated. Multiple column analysis was performed using Kruskal Wallis non-parametric analysis of variance to determine whether significant differences occurred between multiple columns. Where appropriate, MannWhitney rank analysis was used to identify significant differences between columns. Linear regression was used to determine the degree of association between two variables. Fisher's exact test was used for frequency analysis. Significance was taken at $p$ less than 0.05 .

\section{Results}

A dhesion molecule levels in diabetic sera. Soluble ESelectin and sVCAM-1 levels were raised in patients with diabetes compared to control subjects $(p<0.001 ; p<0.001)$. Soluble ICAM levels were no different in patients compared with control subjects $(247.3 \pm 8.6$ vs $244.5 \pm 9.6 ; p>0.05)$. Soluble E-Selectin and sVCAM-1 levels were also raised in patients with retinopathy $(62.9 \pm 2.7 \mathrm{p}<0.001 ; 679.1 \pm 21.3$ $p<0.001$ ) but did not reach statistical significance in those without. Soluble E-Selectin levels were raised in moderate $(p<0.05)$, severe non-proliferative retinopathy $(p<0.001)$ and proliferative diabetic retinopathy $(p<0.05)$ and sVCAM-1 levels were raised in mild $(p<0.01)$, moderate $(p<0.05)$, severe nonproliferative diabetic retinopathy $(p<0.01)$ and proliferative retinopathy $(p<0.01)$ (Table 2$)$.

Serum levels of sE-Selectin also appeared to be related to $\mathrm{HBA}_{1 \mathrm{c}}$ levels $(p<0.05)$ (Fig. 1). There were no associations with any of the other serum adhesion molecules for $\mathrm{HBA}_{1 \mathrm{c}}$, age, duration of diabetes, smoking habit or presence of significant microalbuminuria.

Retinal endothelial cell migration-inducing (ECMI) activity. The first consecutive 56 samples from the patients were tested against a reference standard of pooled NHS for ECMI activity. A value of 1.0 equalled no increase in ECMI activity, a value of less than 
Table 2. Soluble adhesion levels and diabetic retinopathy

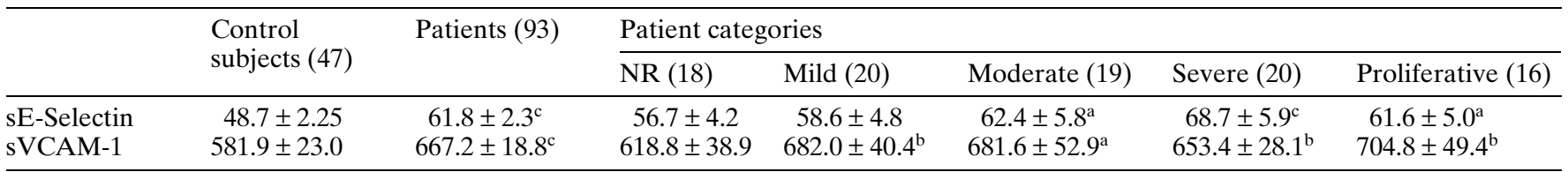

Means \pm SEM. Kruskal Wallis test ANOVA $p<0.01$. Compared to controls ${ }^{a} p<0.05 ;{ }^{b} p<0.01 ;{ }^{c} p<0.001$ (Mann Whitney U test). NR, No retinopathy

Table 3. Retinal endothelial cell migration inducing activity (ECMI) levels and diabetic retinopathy

\begin{tabular}{|c|c|c|c|c|c|c|c|}
\hline & \multirow{2}{*}{$\begin{array}{l}\text { Control } \\
\text { subjects (10) }\end{array}$} & \multirow[t]{2}{*}{ All (56) } & \multicolumn{5}{|c|}{ Patient categories } \\
\hline & & & NR (6) & Mild (15) & Moderate (10) & Severe (12) & Proliferative (13) \\
\hline ECMI (units) & $1.01 \pm 0.06$ & $1.30 \pm 0.03^{\mathrm{b}}$ & $1.16 \pm 0.05$ & $1.27 \pm 0.07^{\mathrm{b}}$ & $1.26 \pm 0.10$ & $1.46 \pm 0.10^{\mathrm{b}}$ & $1.27 \pm 0.06^{\mathrm{a}}$ \\
\hline
\end{tabular}

Means \pm SEM. Kruskal Wallis test ANOVA $p<0.05$. Compared to controls; ${ }^{a} p<0.05 ;{ }^{b} p<0.01$ (Mann Whitney U test). ECMI level $>1.0=$ increased activity. The values from the healthy control sera were not different from the standard pooled normal human serum $(p>0.05)$

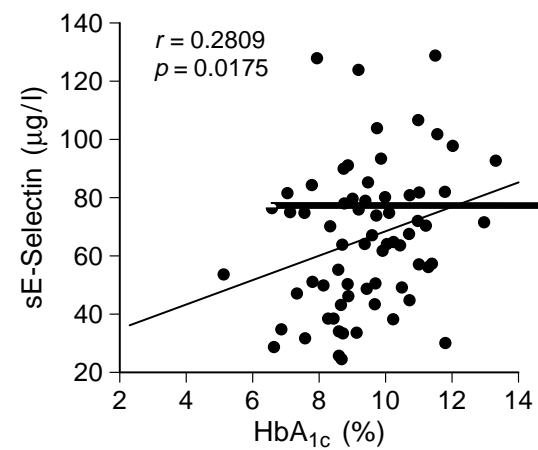

Fig. 1. Association between sE-Selectin $\mu \mathrm{g} / \mathrm{l}$ and $\mathrm{HbA}_{1 \mathrm{c}}$

1.0 indicated inhibition of ECMI activity and a value of more than 1.0 indicated increased ECMI activity. Sera from ten normal healthy individuals were also tested against the reference pooled sera and shown to fall within the "normal" range $(p>0.05)$ (Table 3 ). The results showed that sera from patients with IDDM contained significant levels of migration-inducing (ECMI) activity for retinal endothelial cells in vitro $(p<0.05)$ as previously reported (Table 3$)$ [21]. Furthermore patients with retinopathy were more likely to have higher levels of ECMI activity than non-retinopathy patients $(1.31 \pm 0.04$ vs $1.16 \pm 0.05)$, although this result did not reach statistical significance. (The highest ECMI levels were found in patients with severe non-proliferative diabetic retinopathy $(p<0.01)$ (Table 3$)$.)

Studies on the nature of E CM I activity. In order to determine further the nature of ECMI activity and any possible relationship with raised levels of adhesion molecules in the sera, we conducted blocking studies using monoclonal antibodies.

Serum samples from two patients with active proliferative diabetic retinopathy containing high levels of ECMI activity were incubated with varying concentrations of specific monoclonal antibodies to VCAM and/or E-Selectin and compared for activity in the migration assay with isotype control irrelevant antibody. The results show that antibodies to both ESelectin and VCAM-1 inhibited diabetic serum stimulated retinal endothelial cell migration in a dose-dependent manner (Fig. 2). These experiments were repeated at least three times for each sample and were consistently inhibitory on each occasion. sVCAM-1 appeared to be more effective than sE-Selectin and reduced migration to background levels in the absence of serum.

\section{Discussion}

In this study we have shown that (a) patients with IDDM have raised levels of sVCAM-1 and E-Selectin in their serum which correlate with the severity of their retinopathy; (b) the raised levels of E-Selectin but not sVCAM, correlate moderately with the $\mathrm{HBA}_{1 \mathrm{c}}$; (c) patients with increasingly severe retinopathy have increased levels of ECMI activity in their serum; and (d) ECMI activity can be inhibited by antibodies to SVCAM-1 and E-Selectin.

These results confirm previous studies of diabetic patients which showed that elevated serum sE-Selectin levels occur in NIDDM patients [28] and SVCAM levels in microalbuminuric patients [29]. However, the present study demonstrates a link between severity of retinopathy and elevated adhesion molecule levels, a link which is subtly different for sE-Selectin and sVCAM in that the effect is most marked with preproliferative retinopathy for $\mathrm{sE-Selectin}$ and with proliferative disease for sVCAM. However, there has been controversy as to whether there is any correlation with glucose control and this may reflect differences in the populations studied $[28,30]$. The fact that Steiner's patients [28] were also hypertensive may 


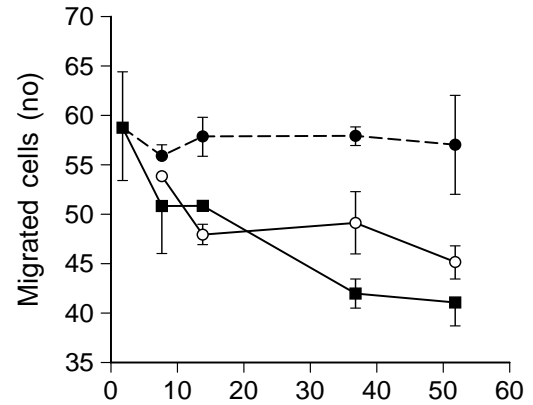

Fig. 2. Antibodies to E-Selectin ( $\square$ ) and VCAM-1 ( $\mathbf{a}$ ) inhibit diabetic serum stimulated retinal endothelial cell migration in a dose-dependent manner compared to $\mathrm{IgG}_{1}$ isotype control (•)

have obscured any association with metabolic control [31]. Our study would seem to confirm Cominacini's work [30] and suggest that there is a moderate correlation between sE-Selectin and metabolic control.

In contrast to the results with sE-Selectin and sVCAM, we were unable to confirm an elevation of sICAM-1 levels previously reported by Lampeter et al. [32]. However, we believe these differences with regard to sICAM levels are due to the different populations studied, in that Lampeter's patients (and their relatives) had recent-onset diabetes, and also possibly to the size of the groups studied [32]. In a further study, sICAM levels were also found not to be different from control subjects in NIDDM patients [28].

Raised levels of sE-Selectin have been demonstrated in diabetic patients independent of hypertension, nephropathy or type of diabetes, and it has been suggested that raised levels may be of prognostic importance in the development of complications [17]. Since in this study, all patients with retinopathy and in particular those with severe non-proliferative retinopathy had raised levels of sE-Selectin, in addition to having raised sVCAM-1 levels especially in association with proliferative retinopathy, the possibility arises of soluble circulating adhesion molecules not only reflecting increasing endothelial cell damage or activation, but also having a pathogenetic role in the induction of angiogenesis.

Raised levels of soluble adhesion molecules in the serum are believed to result from increased endothelial cell expression and shedding following activation $[17,18]$. E-Selectin is expressed only by activated endothelial cells, whereas VCAM-1 and ICAM-1 are also expressed on other cells such as epithelium, macrophages, subsets of CD4 lymphocytes and dendritic cells [33]. E-Selectin expression is transient with peak expression at $4 \mathrm{~h}$ and shedding within $24 \mathrm{~h}$ [34]. VCAM-1 and ICAM-1 peak at 6 to 10 and 12 to $24 \mathrm{~h}$ after being expressed [34, 35]. Elevated levels of sE-Selectin not only occur after activation of the endothelium but may also reflect recent endothelial cell damage [18]. Recent studies indicate that both glucose [11, 36, 37], and advanced glycation end-products may damage endothelium and cause shedding of adhesion molecules $[38,39]$.

Increased expression of adhesion molecules by endothelial cells is likely to increase the adhesion of leukocytes, polymorphonuclear leukocytes in the case of sE-Selectin and activated memory $\mathrm{T}$ cells and monocytes in the case of sVCAM [40]. A role for leukocytes in the pathogenesis of proliferative diabetic retinopathy has been suggested [11, 12]. Under this scheme, adhesion occurs between mutually "activated" leukocytes and endothelium particularly in the small vessels and causes capillary obstruction and occlusion. Monocytes and lymphocytes impeded in their forward movement would be primed to undergo local proliferation within the tissues and release growth factors including angiogenic factors [41]. These would include many of the "recognised" retinal angiogenic factors such as the fibroblast growth factors and vascular endothelial cell growth factor, in addition to many leukocyte-associated cytokines such as tumour necrosis factor-alpha and interleukin-8. In addition, the local shedding of sE-Selectin and sVCAM-1 which also have angiogenic properties [19], would assist in the initiation of the angiogenic response. A similar scheme has been suggested for angiogenesis in the rheumatoid joint $[19,20]$ in which the "angiogenic" activity was reduced by antibodies to sVCAM-1 and E-Selectin. Thus, a systemically induced effect could initiate a local tissue reaction. However, whether shed adhesion molecules in diabetic retinopathy are directly angiogenic or merely promote endothelial cell growth and migration by some other mechanism (for instance by altering the cells adhesion to the extracellular matrix) remains to be determined.

A cknowledgements. The authors thank Mrs. Alison Farrow for ophthalmic photography and Dr. M.J.Williams and Dr. L. E. Murchison for allowing their patients to participate in the study. J.A.Olson and C.M. Whitelaw were supported financially by Scotia Pharmaceuticals Ltd, Woodbridge Meadows, Guildford, Surrey, UK. Dr. S. Urbaniak supplied the blood donor samples.

\section{References}

1. The Diabetes Control and Complications Trial Research Group (1993) The effect of intensive treatment of diabetes on the development and progression of long-term complications in insulin-dependent diabetes mellitus. N Eng $\mathbf{J}$ Med 329: 977-986

2. Frank RN (1994) The aldose reductase controversy. Diabetes 43: 169-172

3. Forrester JV, Knott RM, McIntosh LC (1993) Pathogenesis of proliferative diabetic retinopathy and maculopathy. Elsevier Science Publishers, Amsterdam, pp 178-191

4. Kohner EM (1993) Diabetic retinopathy. BMJ 307: 11951199 
5. Michaelson IC (1948) The mode of development of retinal vessels. Trans Ophthalmol Soc UK 68: 137-138

6. D'Amore P, Orlidge A, Herman I (1989) Growth control in the retinal microvasculature. Progr Retinal Res 7: 233-258

7. D‘Amore P (1994) Mechanisms of retinal and choroidal neovascularisation. Invest Ophth Vis Sci 35: 3974-3979

8. Jaffe A (1987) Cell biology of endothelial cells. Human Pathology 18: 234-239

9. Lupu C, Calb M, Ionescu M, Lupu F (1993) Enhanced prothrombin and intrinsic factor $\mathrm{X}$ activation on blood platelets from diabetic patients. Thromb Haemost 70: 579-583

10. Winocour PD (1992) Platelet abnormalities in diabetes mellitus. Diabetes 42 [Suppl 2]: 26-31

11. Schröder S, Palinski W, Schmid-Schöbein GW (1991) Activated monocytes and granulocytes, capillary non-perfusion and neovascularisation in diabetic retinopathy. Am J Path 139: 81-100

12. Forrester JV, Shafiee AF, Schroder S, Knott R, McIntosh L (1993) The role of growth factors in proliferative diabetic retinopathy. Eye 7: 276-287

13. Tanaka Y, Adams DH, Shaw S (1993) Proteoglycans on endothelial cells present adhesion-inducing cytokines to leucocytes. Immunol Today 14: 111-115

14. Springer TA (1990) Adhesion receptors of the immune system. Nature 346: 424-434

15. Adams DH, Shaw S (1994) Leucocyte-endothelial interactions and regulation of leucocyte migration. Lancet 343: 831-836

16. Seth R, Raymond FD, Makgoba MW (1991) Circulating ICAM-1 isoforms: diagnostic prospects for inflammatory and immune disorders. Lancet 338: 83-84

17. Gearing AJH, Hemmingway I, Pigott R, Hughes J, Rees AJ, Cashman SJ (1992) Soluble forms of vascular adhesion molecules, E-Selectin, ICAM-1 and VCAM-1: pathological significance. Annals New York Acad Sci 667: 324-331

18. Gearing AJH, Newman W (1993) Circulating adhesion molecules in disease. Immunol Today 14: 506-512

19. Koch AE, Halloran MM, Haskell CJ, Shah MR, Polverini PJ (1995) Angiogenesis mediated by soluble forms of E-Selectin and vascular cell adhesion molecule-1. Nature 376: 517-519

20. Ferrara N (1995) Missing link in angiogenesis. Nature 376: 467

21. McIntosh LC, Wheatley SP, Forrester JV (1990) Diabetic serum induces migration but not proliferation of retinal microvascular endothelial cell. Doc Ophthalmol 76: 145

22. Early Treatment for Diabetic Retinopathy Study Research Group (1991) Grading diabetic retinopathy from stereoscopic colour fundus photographs - an extension of the modified Airlie House classification: ETDRS report No. 10. Ophthalmol 91: 786-806

23. Sever P, Beevers G, Bulpitt C, Lever A, Ramsay L, Reid J (1993) Management guidelines in essential hypertension: report of the second working party of the British Hypertension Society. BMJ 306: 983-987

24. Standing SJ, Taylor RP (1992) Glycated haemoglobin: an assessment of high capacity liquid chromatographic and immunoassay methods. Ann Clin Biochem 29: 494-505

25. McHardy K, Gann ME, Ross IS, Pearson DWM (1991) A simple approach to screening for microalbuminuria in a type 1 [insulin-dependent] diabetic population. Ann Clin Biochem 28: 450-455

26. Klein BEK, Davis MD, Segal P, et al. (1984) Diabetic retinopathy: assessment of severity and progression. Ophthalmol 91: 10-17

27. McIntosh LC, Muckersie L, Forrester JV (1988) Retinal capillary endothelial cells prefer different substrates for growth and migration. Tissue Cell 20: 193-209

28. Steiner M, Reinhardt KM, Krammer B, Ernst B, Blann AD (1994) Increased levels of soluble adhesion molecules in type 2 (non-insulin dependent) diabetes mellitus are independent of glycaemic control. Thromb Haemost 72 (6): 979-984

29. Schmidt AM, Crandall J, Hori O, Cao R, Lakatta E (1996) Elevated plasma levels of vascular cell adhesion molecule1 (VCAM-1) in diabetic patients with microalbuminuria: a marker of vascular dysfunction and progressive vascular disease. Brit J Haematol 92 (3): 747-750

30. Cominacini L, Fratta Pasini A, Garbin U et al. (1995) Elevated levels of soluble E-Selectin in patients with IDDM and NIDDM: relation to metabolic control. Diabetologia 38: 1122-1124 (Letter)

31. Blann AD, Tse W, Maxwell SJR, Waite MA (1994) Increased levels of the soluble adhesion molecule E-selectin in essential hypertension. J Hypertension 12: 925-928

32. Lampeter ER, Kishimoto TK, Rothlein R et al. (1992) Elevated levels of circulating adhesion molecules in IDDM patients and in subjects at risk for IDDM. Diabetes 41 (12): 1668-1671

33. Hogg N, Landis RC (1993) Adhesion molecules in cell interactions. Curr Op Immunol 5: 383-391

34. Leewenberg JFM, Smeets EF, Nefjes JJ, Shaffer T, Cinek T, Jeunhomme TMAA (1992) E-Selectin and intercellular adhesion molecule-1 are released by activated human endothelial cells in vitro. Immunology 77: 543-549

35. Osborn L, Hession C, Tizard R, et al. (1989) Direct expression cloning of vascular cell adhesion molecule-1, a cytokine-induced endothelial protein that binds to lymphocytes. Cell 59: 1203-1211

36. Gilcrease MZ, Hoover RL (1992) Human monocyte interactions with non-enzymatically glycated collagen. Diabetologia 35: 160-164

37. Kim JA, Berliner JA, Natajaran RD, Nadler JL (1995) Evidence that glucose increases monocyte binding to aortic endothelial cells. Diabetes 43: 1103-1107

38. Baumgartner-Parzer SM, Wagner L, Pettermann M, Gessl A, Waldhäusl W (1995) Modulation by high glucose of adhesion molecule expression in cultured endothelial cells. Diabetologia 38: 1367-1370

39. Schmidt AM, Hori O, Chen JX et al. (1995) Advanced glycation end products interacting with their endothelial receptor induce expression of vascular cell adhesion molecule-1 [VCAM-1] in cultured endothelial cells and in mice. J Clin Invest 96: 1395-1403

40. Springer TA (1994) Traffic signals for lymphocyte recirculation and leukocyte emigration: the multistep paradigm. Cell 76: 301-314

41. Sunderkotter C, Goebler M, Schulze-Osthoff K, Bhardwaj R, Sorg C (1991) Macrophage-derived angiogenesis factors. Pharmac Ther 51: 195-216 